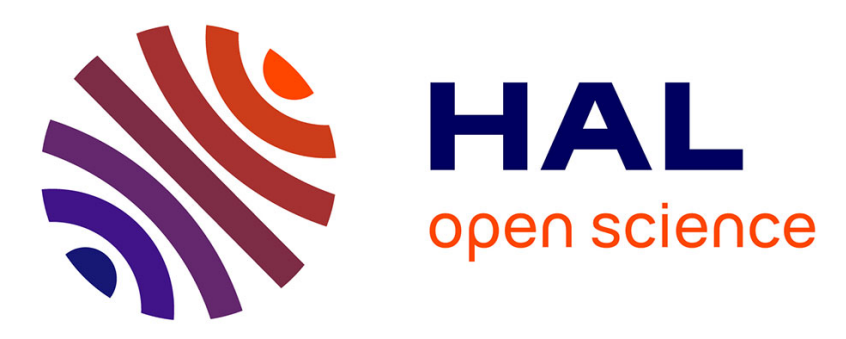

\title{
Influence of Surface Compositions on the Reactivity of Pyrite toward Aqueous U(VI)
}

Bin Ma, Alejandro Fernandez-Martinez, Mingliang Kang, Kaifeng Wang, Aled Lewis, Thierry Maffeis, Nathaniel Findling, Eduardo Salas-Colera, Delphine Tisserand, Sarah Bureau, et al.

\section{To cite this version:}

Bin Ma, Alejandro Fernandez-Martinez, Mingliang Kang, Kaifeng Wang, Aled Lewis, et al.. Influence of Surface Compositions on the Reactivity of Pyrite toward Aqueous U(VI). Environmental Science and Technology, 2020, 54 (13), pp.8104-8114. 10.1021/acs.est.0c01854 . hal-03043988

\section{HAL Id: hal-03043988 \\ https://hal.science/hal-03043988}

Submitted on 5 Jan 2021

HAL is a multi-disciplinary open access archive for the deposit and dissemination of scientific research documents, whether they are published or not. The documents may come from teaching and research institutions in France or abroad, or from public or private research centers.
L'archive ouverte pluridisciplinaire HAL, est destinée au dépôt et à la diffusion de documents scientifiques de niveau recherche, publiés ou non, émanant des établissements d'enseignement et de recherche français ou étrangers, des laboratoires publics ou privés. 


\section{The influence of surface compositions on the reactivity of}

\section{pyrite toward aqueous $\mathrm{U}(\mathrm{VI})$}

Bin Ma ${ }^{\text {a }}$, Alejandro Fernandez-Martinez ${ }^{\text {a }}$, Mingliang Kang ${ }^{\text {b, }}$, Kaifeng Wang ${ }^{\text {a,c }}$, Aled R. Lewis $^{\mathrm{d}}$, Thierry G.G. Maffeis ${ }^{\mathrm{d}}$, Nathaniel Findling ${ }^{\text {a }}$, Eduardo Salas-Colera ${ }^{\mathrm{e}, \mathrm{f}}$, Delphine Tisserand $^{\text {a }}$, Sarah Bureau ${ }^{\text {a }}$, Laurent Charlet ${ }^{\text {a }}$

${ }^{a}$ Univ. Grenoble Alpes, Univ. Savoie Mont Blanc, CNRS, IRD, IFSTTAR, ISTerre, 38000 Grenoble, France

${ }^{\mathrm{b}}$ Sino-French Institute of Nuclear Engineering and Technology, Sun Yat-sen University, Zhuhai 519082, China

${ }^{c}$ Decommissioning Engineering Technology Center, China Institute of Atomic Energy, 102413, Beijing, China

${ }^{\mathrm{d}}$ Systems and Process Engineering Centre, College of Engineering, Swansea University, Fabian Way, Swansea SA1 8EN, UK

${ }^{\text {e }}$ Instituto de Ciencia de Materiales de Madrid, CSIC, Sor Juana Inés de la Cruz 3, 28049 , Cantoblanco Madrid, Spain.

${ }^{\mathrm{f}}$ Spanish CRG BM25 SpLine Beamline at the ESRF, 71 Avenue de Martyrs, F-38043 Grenoble, France. 


\section{ABSTRACT}

Pyrite plays a significant role in governing the mobility of toxic uranium in anaerobic environment via an oxidation-reduction process occurring at the mineral-water interface, but the factors influencing the reaction kinetics remain poorly known. In this study, natural pyrites with different impurities ( $\mathrm{Pb}, \mathrm{As}$ and $\mathrm{Si})$ and different surface pretreatments were used to react with aqueous $\mathrm{U}(\mathrm{VI})$ from $\mathrm{pH} \sim 3.0$ to $\sim 9.5$. Both aqueous and solid results indicated that freshly crushed pyrites, which do have more surface $\mathrm{Fe}^{2+} / \mathrm{Fe}^{3+}$ and $\mathrm{S}^{2-}$ sites that were generated from breaking $\mathrm{Fe}(\mathrm{S})-\mathrm{S}$ bonds during ball-milling, exhibited a much stronger reactivity than those treated with acid-washing. Besides, U(VI) reduction which involves the possible intermediate $\mathrm{U}(\mathrm{V})$ and the formation of hyperstoichiometric $\mathrm{UO}_{2+\mathrm{x}}(\mathrm{s})$ was found to preferentially occur on $\mathrm{Pb}$ - and As-rich spots on the pyrite surface, suggesting that the impurity doping could act as reactive sites due to the generation of lattice defects and galena- and arsenopyritelike local configurations. These reactive surface sites can be removed by acid-washing, leaving a pyrite surface nearly inert towards aqueous $\mathrm{U}(\mathrm{VI})$. Thus, reactivity of pyrite towards $\mathrm{U}(\mathrm{VI})$ is largely governed by its surface compositions, which provides an insight on the chemical behavior of both pyrite and uranium in various environments. 


\section{INTRODUCTION}

Pyrite $\left(\mathrm{FeS}_{2}\right)$, the Earth's most abundant sulfide mineral, is known to be one of the important minerals buffering the reducing conditions in nuclear waste repositories where it is present in host claystone or granite as well as in near-field bentonite materials. ${ }^{1}$ Besides, pyrite can also be present in sulfide-rich blended cement that could be used as repository construction material. $^{2}$ Previous studies have confirmed that pyrite can effectively immobilize redox-sensitive radionuclides ( such as ${ }^{79} \mathrm{Se}^{3,4}$ and ${ }^{99} \mathrm{Tc}^{5}$ ) via reductive precipitation.

Uranium (U), accounting for $96 \mathrm{wt} . \%$ of the spent nuclear fuel and receiving extensive attention in the geological disposal of nuclear waste ${ }^{6-9}$ is also redox-sensitive and its solubility is largely dependent on its oxidation state. U mainly exists as $\mathrm{U}(\mathrm{VI})$ and $\mathrm{U}(\mathrm{IV})$ or other aliovalent oxides with $\mathrm{U}(\mathrm{V}){ }^{10}$ in the natural environment. The formation of ternary complexes of hexavalent uranium ion $\left(\mathrm{UO}_{2}{ }^{2+}\right)$ with $\mathrm{CO}_{3}{ }^{2-}$ and alkaline earth metals in the groundwaterrock system can further enhance the solubility of $\mathrm{U}(\mathrm{VI}){ }^{11}$. In contrast, except for coffinite $\left(\mathrm{USiO}_{4}\right)$ nanoparticles ${ }^{12}$ or U(IV)-bearing colloids, ${ }^{13} \mathrm{UO}_{2}$ and other aliovalent oxides (e.g., $\mathrm{U}_{4} \mathrm{O}_{9}, \mathrm{U}_{3} \mathrm{O}_{7}$, or $\mathrm{U}_{3} \mathrm{O}_{8}$ ) are nearly insoluble under weakly acidic to alkaline conditions. Thus, reductive precipitation, especially by the ubiquitous $\mathrm{Fe}(\mathrm{II})$-bearing minerals in the geologic environment, is considered an effective way to immobilize the toxic uranium. Surface catalysis of $\mathrm{U}(\mathrm{VI})$ reduction by $\mathrm{Fe}(\mathrm{II}),{ }^{14}$ or abiotic reduction of $\mathrm{U}(\mathrm{VI})$ by $\mathrm{Fe}(\mathrm{II})$-bearing minerals such as magnetite ${ }^{15}$ and mackinawite, ${ }^{16}$ has long been recognized in this respect. Experimental and theoretical works have further revealed that intermediate $U(V)$ can be stabilized by arrangement in a uranate-like octahedral structure. ${ }^{15,17,18}$

Pyrite is frequently found in association with uranium ore deposits in both metamorphic and sedimentary settings. ${ }^{19,20}$ Thermodynamically, $\mathrm{UO}_{2}$ is the most stable mineral in pyritecontaining systems in a wide $\mathrm{pH}$ range, ${ }^{21}$ in particular at a relatively high $\mathrm{U}$ concentration. ${ }^{22}$ Uptake and partial reduction of U(VI) by pyrite was firstly reported under acidic conditions 
(pH 5.1-6.3) after equilibrating for 6-8 days. ${ }^{23}$ After, the formation of a hyperstoichiometric $\mathrm{UO}_{2+\mathrm{x}}(\mathrm{s})$ product on natural pyrite was confirmed at $\mathrm{pH}$ 3.6-6.1 over short reaction times (i.e., 4 or 48 hours). ${ }^{24,25}$ Besides, freshly polished pyrite surfaces were reported as efficient scavengers for $\mathrm{U}(\mathrm{VI})$ from solution at $\mathrm{pH} 4.8,{ }^{26}$ and dissolved organic matter was found to increase the final uranium solution concentration and decrease the fraction of uranium(IV) on the pyrite solid surface. ${ }^{27}$ In contrast, a previous study demonstrated that U(VI) reduction by synthetic and natural pyrite samples with acid-washed surfaces was largely inhibited under most pH conditions. ${ }^{21}$ These discrepant observations impel us to clarify the factors controlling the reactivity of pyrite.

It is generally accepted that the kinetics of redox reactions occurring at the mineral-water interface are largely dependent on the reactivity of surface sites, ${ }^{23}$ which might be influenced by the treatment procedures. In addition, natural pyrite typically contains a host of minor and trace elements, such as $\mathrm{As}, \mathrm{Co}, \mathrm{Pb}$, and $\mathrm{Zn}$. The variability in the chemical composition can result in variations in physico-chemical properties, ${ }^{28}$ and in particular, the oxidation rates can be enhanced for As- and Co-doped pyrite. ${ }^{29}$ A previous study compared the oxidation kinetics between varying impurities-doped and undoped pyrites, concluding that pure pyrite is less reactive than As-containing pyrite. ${ }^{30}$ To date, the factors influencing the oxidation-reduction rates of pyrite toward aqueous U(VI) are poorly known and not sufficiently supported by experimental data. In order to better understand the role of pyrite in affecting the mobility of uranium in the environment, we investigated the influence of $\mathrm{S}^{2-}$ species and impurities $(\mathrm{Pb}$, As and $\mathrm{Si}$ ) on pyrite surfaces on the reduction rate of aqueous $\mathrm{U}(\mathrm{VI})$.

\section{MATERIALS AND METHODS}

\subsection{Materials}

Analytical grade $\mathrm{UO}_{2}\left(\mathrm{NO}_{3}\right)_{2}$ stock solution (1000 ppm U in $\left.2 \% \mathrm{HNO}_{3}\right), \mathrm{Na}_{2} \mathrm{CO}_{3}, \mathrm{NaOH}$, and $\mathrm{HCl}$ were purchased from Sigma Aldrich. Deionized water $(18.2 \mathrm{M} \Omega \cdot \mathrm{cm})$ was degassed by 
first boiling and then cooling with continuous argon purging before use for solution preparation. Three types of natural pyrite were collected: (i) a commercial pyrite containing $\mathrm{Pb}$ and free of $\mathrm{As}$ and $\mathrm{Si}$ from Alfa Aesar, named Pb-pyrite; (ii) an As-rich pyrite from the Jiguanshan ore mine (Tongling, China), called hereafter As-pyrite; and (iii) a $\mathrm{SiO}_{2}$-coexisting pyrite from the Shizishan ore mine (Tongling, China), named Si-pyrite. The As-pyrite blocks were crushed, sieved, and magnetically separated in the air, following the procedures described previously. ${ }^{4}$ Similar pretreatment was applied to the Si-pyrite blocks, while no pretreatment was carried out for the commercial $\mathrm{Pb}$-pyrite. The sizes of the obtained particles were 1.5-4.8 mm, 0.13-0.15 mm, and 5.0-10.0 mm for Pb-pyrite, As-pyrite, and Si-pyrite, respectively. After washing with $0.2 \mathrm{M} \mathrm{HCl}$, degassed water and acetone in sequence, the dried pyrite grains were ground with a planetary ball mill (Pulverisette-7, Fritsch GmbH, Germany) under $\mathrm{N}_{2}$-atmosphere protection. Two kinds of pyrite powders were employed for sorption experiments. The first one (labeled as Type I pyrite) was prepared with the same washing procedure again and then dried. The second one (labeled as Type II pyrite) was used directly after ball milling. All preparation procedures for Type I and Type II pyrite powders were performed under $\mathrm{N}_{2}$-atmosphere protection or in a glove box $\left(\mathrm{O}_{2}<2 \mathrm{ppm}\right)$. Both were stored under anoxic conditions.

The specific surface area of the ground pyrite powder was measured by the BrunauerEmmett-Teller (BET) $\mathrm{N}_{2}$-absorption method. X-ray diffraction (XRD) analysis was used to characterize the mineral components. The main elements Fe and $\mathrm{S}$ as well as minor and trace elements ( $\mathrm{As}, \mathrm{Co}, \mathrm{Ni}, \mathrm{Cu}, \mathrm{Pb}$, etc.) in the pyrite were identified and quantified by inductively coupled plasma optical emission spectrometry (ICP-OES, Varian 720-ES apparatus) after digestion in aqua regia. Certified single element standards (Sigma Aldrich) were used for quality control, allowing a deviation of no more than $10 \%$ with respect to the certified values.

\subsection{Sorption experiments}


Sorption experiments were conducted at $\mathrm{pH} \sim 3.0, \sim 4.5, \sim 6.5$, and $\sim 9.5$ at $25{ }^{\circ} \mathrm{C}$ under constant shaking in a $\mathrm{N}_{2}$-filled glove box $\left(\mathrm{O}_{2}<2 \mathrm{ppm}\right)$. Prior to introducing $\mathrm{U}(\mathrm{VI})$, the pyrite powder was equilibrated with $0.01 \mathrm{M} \mathrm{NaCl}$ at the given $\mathrm{pH}$ values for 2 days. Identical solidto-liquid (S/L) ratios of $10 \mathrm{~g} \cdot \mathrm{L}^{-1}$ and initial $\mathrm{U}(\mathrm{VI})$ concentrations of $0.1 \mathrm{mM}$ were applied to all reactors. Spontaneous precipitation of U(VI) tends to occur at a relatively high $\mathrm{pH}$. For the reactors at $\mathrm{pH} \sim 6.5$ and $\sim 9.5$, an extra $1.0 \mathrm{mM} \mathrm{Na}_{2} \mathrm{CO}_{3}$ was added to increase the solubility of $\mathrm{U}(\mathrm{VI})$. After adding a certain portion of the $\mathrm{UO}_{2}\left(\mathrm{NO}_{3}\right)_{2}$ stock solution, a $5 \mathrm{~mL}$ aliquot of suspension was sampled and filtered through a $0.22 \mu \mathrm{m}$ pore size membrane filter. Subsequently, the solution $\mathrm{pH}$ was quickly adjusted back to the given reaction $\mathrm{pH}$ values using $\mathrm{NaOH}$ and $\mathrm{HCl}$ solution. At each defined time interval, the $\mathrm{pH}$ was measured and readjusted if necessary; then, a $5 \mathrm{~mL}$ aliquot of suspension was sampled by filtration. Complementary experiments were performed simultaneously to determine the concentrations of sulfur species before and after adding $\mathrm{U}(\mathrm{VI})$ at $\mathrm{pH} \sim 3.0$ and $\sim 4.5$.

The solution $\mathrm{pH}$ was measured by a combined glass Micro-pH electrode (Metrohm 6.0234.100) immediately after calibration by $\mathrm{pH}$ standard solutions. The filtrate samples for all reactors were analyzed by ICP-OES to determine the concentrations of total U, Fe, S, As, $\mathrm{Co}, \mathrm{Pb}$, and $\mathrm{Ni}$. Aqueous sulfide was analyzed by the methylene blue method. ${ }^{31}$ In order to precipitate and stabilize the aqueous S(-II), a certain amount of $5 \mathrm{wt} \%$ zinc acetate solution was added immediately into the freshly obtained filtrates. Elemental sulfur was extracted by perchloroethylene and subsequently analyzed by high-performance liquid chromatography (HPLC) with a Varian ProStar 230 apparatus coupled with a UV/Visible detector (Perkin Elmer 785A). ${ }^{32}$ The U(VI)-reacted pyrite in each reactor was collected by vacuum filtration through a $0.22 \mu \mathrm{m}$ nitrocellulose membrane and then dried and stored in the glove box. Special care was taken to prevent any possible oxidation for the subsequent solid characterization.

\subsection{Spectroscopic and microscopic analyses}


X-ray photoelectron spectroscopy (XPS) measurements were performed on the pristine and the selected U(VI)-reacted pyrites. Samples were transported to the XPS facility in a $\mathrm{N}_{2}$-filled metallic jar, pasted flat on double-face carbon tape, and then rapidly transferred into the XPS chamber under the protection of high-purity nitrogen. The XPS spectra were recorded using a Kratos AXIS Supra electron spectrometer. A monochromated Al Ka source, a hybrid lens system providing an elliptic analysis area of $0.3 \times 0.8 \mathrm{~mm}^{2}$, and a charge neutralizer were used. The pass energy was $160 \mathrm{eV}$ for survey scans and $20 \mathrm{eV}$ for regions. The XPS data were processed using the CasaXPS software. The binding energy (BE) scale was calibrated with the C1s line of aliphatic carbon, which was set at $284.8 \mathrm{eV}$. The Shirley background algorithm was used to construct the baselines. The Gaussian/Lorentzian product formula, with GL(30) mixing, was applied to describe the line shapes. The U(4f) spectra were fitted with a spin-orbit splitting of $10.89 \mathrm{eV}$, a fixed intensity ratio of $4: 3\left(4 f_{7 / 2}: 4 f_{5 / 2}\right)$, and identical full width at half of maximum (FWHM) values for the doublet peaks. The $\mathrm{S}(2 p)$ spectra were fitted with $\mathrm{S}\left(2 p_{3 / 2}\right)$ and $\mathrm{S}\left(2 p_{1 / 2}\right)$ spin-orbit doublets, with a fixed 2:1 intensity ratio and a $1.18 \mathrm{eV}$ energy separation. The uncertainty of BE on the fit peak was $\pm 0.2 \mathrm{eV}$.

Sorbed $\mathrm{U}$ speciation on $\mathrm{Pb}$-pyrite at different $\mathrm{pH}$ values was characterized by $\mathrm{U}_{3}$-edge $(17166 \mathrm{eV}) \mathrm{X}$-ray absorption near edge structure (XANES) spectroscopy analyses. The measurements were conducted at the SpLine Spanish CRG Beamline (BM25A) at the European Synchrotron Radiation Facility (ESRF), Grenoble, France. Energy calibration for the $\mathrm{U}_{3_{3}}$ edge was achieved by setting the inflection point of an yttrium (Y) foil spectrum to $17038 \mathrm{eV}$. Reference spectra of solid $\mathrm{U}_{3} \mathrm{O}_{8}$ and $\mathrm{U}_{4} \mathrm{O}_{9}{ }^{10}, \mathrm{UO}_{2}\left(\mathrm{NO}_{3}\right)_{2}{ }^{33}$ and $\mathrm{UO}_{2}{ }^{34}$ were used for comparison. The schoepite $\left(\mathrm{UO}_{3} \cdot 2 \mathrm{H}_{2} \mathrm{O}\right)$ reference (Figure S1) was precipitated by neutralizing the acidic 1000 ppm $\mathrm{UO}_{2}\left(\mathrm{NO}_{3}\right)_{2}$ solution with $1 \mathrm{M} \mathrm{NaOH}$. The dried samples were sealed doubleside using Kapton tape in the glove box and then transferred in an anaerobic metallic jar to the synchrotron facility. All the samples were measured in fluorescence mode, while the refer- 
ences prepared as pellets by diluting the solids in cellulose were measured in transmission mode. A Sirius liquid nitrogen cooled $\mathrm{Si}(\mathrm{Li})$ 13-multielement solid-state X-ray detector from e2v was used for data collection. During the measurement, samples were always under a $\mathrm{N}_{2}$ atmosphere protection. The Demeter software package was used for the data integration and reduction of XANES (Athena). ${ }^{35}$ A linear combination fit (LCF) was applied to the XANES spectra to identify and quantify the U solid speciation. The LCF was performed starting with the best two references, selected using crystal-chemistry concepts, and the energy shift of reference was fixed. One more reference spectrum $(n+1)$ would be added, only if a reduced $\chi$ square $\left(\chi_{v}^{2}\right)$ value of at least $15 \%$ lower than that of the best $n$-component fit was obtained (i.e., a significantly better fit was achieved). ${ }^{36}$ The statistical significance of adding a standard was verified using F-tests. ${ }^{37}$ We note here that more advanced analyses such as iterative transformation factor analysis were not performed due to the limited number of samples and standards.

Pair distribution function (PDF) analysis of high-energy X-ray scattering (see experimental details in reference ${ }^{38}$ ) and sulfur K-edge XANES and extended X-ray absorption fine structure (EXAFS) analyses (see experimental details in reference ${ }^{2}$ ) were performed to check the crystallinity of pristine pyrites. The morphology of the pristine and U(VI)-reacted pyrite powders was characterized by scanning electron microscopy (SEM, Hitachi S4800). The fine powder samples were spread across double-sided carbon tapes, which were attached to silicon substrates. The corresponding chemical composition was analyzed using an energy dispersive $\mathrm{X}$-ray spectrometer (EDX).

\section{RESULTS AND DISCUSSION}

\subsection{Pyrite characterization}

XRD patterns indicated that the $\mathrm{Pb}$-pyrite and As-pyrite used for the reaction were mineralogically pure, whereas visible diffraction peaks of crystalline alpha-quartz were ob- 
served for the Si-pyrite. No other crystalline phase was detected (Figure S2). The sharp XRD peaks suggested a high and comparable crystallinity for all the pyrites. PDF analysis was further used to check any existence of amorphous/nano-crystalline phases and of lattice defects. As shown in Figure S3, the three Type II pyrites resulted in almost the same PDF patterns, with all their correlation peaks matching well with the simulated PDF of single-crystal pyrite. ${ }^{39}$ Besides, S K-edge XANES-EXAFS spectra of Type II Pb-pyrite and As-pyrite were well-matched with each other (Figure S4), indicating that the atomic arrangement of their bulk phases were nearly identical. The EXAFS spectra were collected up to $k \sim 8 \AA^{-1}$, allowing the quantification of at least the first neighbor atoms. ${ }^{40}$ By the quantitative EXAFS fit (Table $\mathrm{S} 1)$, the first shell can be reproduced by coordination number $(\mathrm{CN})$ of $\sim 1 \mathrm{~S}$ atom at a bond length of $\mathrm{d}_{\mathrm{S}-\mathrm{S}}=2.13 \AA$ and $\mathrm{CN}$ of $\sim 3 \mathrm{Fe}$ atoms at $\mathrm{d}_{\mathrm{S}-\mathrm{Fe}}=2.24 \AA$, in accordance with the perfect lattice of highly crystalline pyrite. It suggested that the three pyrites possessed a similar high crystallinity. The relatively little lattice defect and impurity doping were invisible in the PDF and S K-edge EXAFS analyses.

The specific surface areas of the ground $\mathrm{Pb}-$, As-, and Si-pyrites were measured as 0.8, 0.6, and $0.9 \mathrm{~m}^{2} \mathrm{~g}^{-1}$, respectively. ICP-OES analysis of the acid digestion solution revealed $\sim 0.10$ wt $\% \mathrm{~Pb}$ for Pb-pyrite (i.e., $\mathrm{FeS}_{2} \mathrm{~Pb}_{0.00060}$ ), $\sim 1.66 \mathrm{wt} \%$ As and $\sim 0.12 \mathrm{wt} \% \mathrm{~Pb}$ for As-pyrite (i.e., $\mathrm{FeS}_{2} \mathrm{As}_{0.027} \mathrm{~Pb}_{0.00070}$ ), and $\sim 0.10$ wt $\% \mathrm{~Pb}$ for $\mathrm{Si}$-pyrite (i.e., $\mathrm{FeS}_{2} \mathrm{~Pb}_{0.00059}$ ), while other elements were below the detection limits of the ICP-OES analysis. As reported previously, arsenian pyrite may contain up to $10 \% \mathrm{As}$, and $\mathrm{Pb}$-containing pyrite is generally arsenicrich. ${ }^{28}$ Thus, the $\mathrm{Pb}$ and As impurity levels observed in this study are in the range found for natural pyrites.

\subsection{Aqueous results of batch sorption experiments}


The evolutions of aqueous $\mathrm{U}, \mathrm{Fe}$ and $\mathrm{S}$ in different reactors are illustrated in Figure 1 (detailed data are shown in Tables $\mathrm{S} 2$ and $\mathrm{S} 3$ ). $\mathrm{Pb}$ and As were not detected probably due to the scarcity of impurities contained in the pyrites and the noncongruent dissolution of pyrite.

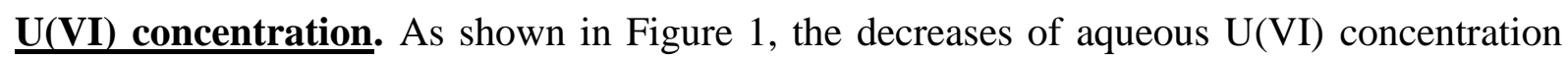
([U(VI) $]_{\mathrm{aq}}$ ) at $\mathrm{pH} \sim 3.0, \sim 4.5$, and $\sim 9.5$ for Type II pyrites are larger than those for Type I pyrites. For Type I Pb- and As-pyrites at $\mathrm{pH} \sim 3.0$ and $\sim 4.5$ and Si-pyrite at $\mathrm{pH} \sim 3.0,[\mathrm{U}(\mathrm{VI})]_{\mathrm{aq}}$ remained nearly invariant after a slight decrease in the first 24.5 hours. Conversely, [U(VI) $]_{\mathrm{aq}}$ decreased dramatically to a low level within the first 24.5 hours for Type II $\mathrm{Pb}$ - and Aspyrites at $\mathrm{pH} \sim 4.5$. The rapid uptake of aqueous $\mathrm{U}(\mathrm{VI})$ by Type II As-pyrite at $\mathrm{pH} \sim 4.5$ was further confirmed by the complementary experiments (Table S4). Compared with the other two Type II pyrites, Type II As-pyrite immobilized the least amount of $U$ at $\mathrm{pH} \sim 3.0$. This probably results from the electrostatic repulsion or a relatively weak surface attraction as cationic $\mathrm{UO}_{2}{ }^{2+}$ is predominant (Figure S5) and the pyrite surface may be positively charged at this low $\mathrm{pH}$. Indeed, the point of zero charge (PZC) values of pyrite and arsenopyrite are approximately pH 2.0 and 5.4, respectively. ${ }^{41}$ Arsenic substitution is expected to increase the $\mathrm{pH}_{\mathrm{PZC}}$ of pyrite since it has a local order similar to that of arsenopyrite. ${ }^{42,43}$ At $\mathrm{pH} \sim 6.5$ a significant decrease in $[\mathrm{U}(\mathrm{VI})]_{\mathrm{aq}}$ was observed for both Type I and Type II pyrites, which might be mainly explained by the spontaneous precipitation of $\mathrm{U}(\mathrm{VI})$-containing phases such as schoepite that shows a relatively low solubility at this $\mathrm{pH}$ condition (Figure S5). In addition, we cannot exclude the possible occurrence of surface sorption on the formed Fe(III) (oxyhydr)oxides at this $\mathrm{pH}$ condition (see section 3.3 below). At $\mathrm{pH} \sim 9.5$, the sorption also proceeded relatively slowly, especially for Type I pyrites, which could be mainly explained by the negatively charged pyrite surface and the prevalence of anionic U(VI) species under alkaline conditions (Figure S5). 
Fe concentration. The concentration of aqueous $\mathrm{Fe}\left([\mathrm{Fe}]_{\mathrm{aq}}\right)$ was strongly $\mathrm{pH}$-dependent for both types of pyrites. Less aqueous Fe was released from pyrites with increasing $\mathrm{pH}$. Besides, much higher $[\mathrm{Fe}]_{\mathrm{aq}}$ was detected in Type II pyrite reactors compared to Type I pyrite reactors. In addition to the reaction with $\mathrm{U}(\mathrm{VI})$, this could be explained mainly by the reaction of surface $\mathrm{Fe}^{3+}$ with $\mathrm{S}^{2-}$ upon contact with solution. Indeed, during the anoxic grinding process, the breaking of $\mathrm{Fe}(\mathrm{S})-\mathrm{S}$ bonds would result in an electron transfer from iron to sulfur and thus the formation of $\mathrm{S}^{2-}$ and $\mathrm{Fe}^{3+}$ sites on the pyrite surfaces. ${ }^{44}$ This is further confirmed by the generally high $[\mathrm{Fe}]_{\mathrm{aq}}$ and $[\mathrm{S}]_{\mathrm{aq}}$ (the concentration of aqueous $\mathrm{S}$ ) observed in Type II pyrite reactors before introducing $\mathrm{U}(\mathrm{VI})$ (Table S3), although no $\mathrm{SO}_{3}{ }^{2-} / \mathrm{SO}_{4}{ }^{2-}$ was detected on the surface of pristine Type II pyrite (Figure S6).

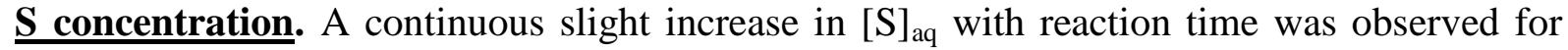
Type I pyrites, probably caused mainly by the non-oxidative dissolution of pyrites. The $[\mathrm{S}]_{\mathrm{aq}} /[\mathrm{Fe}]_{\mathrm{aq}}$ ratio in each reactor was quite lower than 2.0 (Tables S2 and S3), indicating a non-congruent dissolution of the pyrites. A large quantity of aqueous $\mathrm{S}\left(\sim 2.4 \times 10^{-4} \mathrm{M}\right)$ was observed in Type II Pb-pyrite suspensions, which might be mainly ascribed to the oxidation of surface $\mathrm{S}^{2-}$ by surface $\mathrm{Fe}^{3+}$.

For all Type II pyrite reactors, it is worth noting that an obvious decrease of $[\mathrm{S}]_{\mathrm{aq}}$ at the early stage of reaction can be observed under all $\mathrm{pH}$ conditions. This decrease could be explained by the oxidation of aqueous $\mathrm{S}(-\mathrm{II})$ to elemental sulfur $\left(\mathrm{S}^{0}\right)$ by the added U(VI). ${ }^{45,46}$ Oxidation of surface $\mathrm{S}^{2-}$ to $\mathrm{SO}_{3}{ }^{2-} / \mathrm{SO}_{4}{ }^{2-}$ by the surface $\mathrm{Fe}^{3+}$ at the pyrite-water interface cannot consume all $\mathrm{S}^{2-}$, which could result in release of the residual surface $\mathrm{S}^{2-}$ species to the solution. Aqueous sulfide is reactive and can be rapidly oxidized by aqueous $U(V I)$ to $S^{0}$ in a homogeneous system. $^{45,46}$ This explanation was further verified by the analysis of sulfur species (Table S5), as [MBS] (represents the concentration of methylene-blue-detectable sulfur, i.e., total S(-II) species) decreased from 11.0 to $1.3 \mu \mathrm{M}$ at $\mathrm{pH} \sim 3.0$ and from 8.5 to $0.3 \mu \mathrm{M}$ at $\mathrm{pH} \sim 4.5$ after 
the addition of U(VI) in Type II As-pyrite reactors. Meanwhile, a significant amount of $\mathrm{S}^{0}$ was detected (Table S5). In contrast, the [MBS] values were immeasurable or negligible in the case of Type I Pb- and As-pyrites (Table S5). The concentrations of sulfur oxyanions were not measured directly but can be estimated by the determined $[\mathrm{S}]_{\mathrm{aq}}$ and $[\mathrm{MBS}]$ for samples listed in Tables S4 and S5.

\subsection{XPS surface features}

In line with the minor decreases of $[\mathrm{U}(\mathrm{VI})]_{\mathrm{aq}}$, solid concentrations of sorbed uranium in a few reacted Type I pyrites were too low to be detected by XPS. The representative XPS U(4f) spectra of selected samples are shown in Figure 2 and the rest are in Figure S7. The same notation strategy was used for all the samples, e.g., Pb-pI-pH6.5 represents Type I Pb-pyrite at $\mathrm{pH} \sim 6.5$. Two main peaks of $\mathrm{U}\left(4 f_{7 / 2}\right)$ spectrum can be fitted at $381.9 \pm 0.4$ and $380.5 \pm 0.2 \mathrm{eV}$, which are corresponding to unreduced $\mathrm{U}(\mathrm{VI})$ and reduced uranium (labeled as $\mathrm{U}(\mathrm{IV} / \mathrm{V})$ ), respectively. Area percentages of XPS peaks are shown in Table S6. Previous studies by cyclic voltammetry verified that $\mathrm{U}(\mathrm{VI})$ can be reduced to $\mathrm{U}(\mathrm{V})$ on the surface of pyrite. ${ }^{47,48}$ However, the exact reduced $U$ species were difficult to be identified as the binding energies for $U(V)$ and U(IV) are very close. ${ }^{49}$ Shoulder peaks fitted at $385.0 \pm 1.0 \mathrm{eV}$ were probably ascribed to the U(VI) satellite signal. The satellite peaks could also help to determine the valences of reduced U. ${ }^{17,50,51}$ However, this was largely limited by the predominance of $\mathrm{UO}_{2+\mathrm{x}}$ product formed in this study. ${ }^{51}$ Relatively weak peaks at $\sim 389 \mathrm{eV}$ and $\sim 387 \mathrm{eV}$, possibly attributing to $\mathrm{U}\left(4 f_{7 / 2}\right)$ satellites of $\mathrm{U}(\mathrm{V})$ and $\mathrm{U}(\mathrm{IV})$, respectively, were observed only for As-pII-pH4.5 and Pb-pII-pH3.0 that had a relatively high content of reduced uranium. ${ }^{49}$ At each $\mathrm{pH}$ condition, the $\mathrm{U}(\mathrm{IV} / \mathrm{V}) / \mathrm{U}(\mathrm{VI})$ ratios of Type II pyrites are higher than that of Type I pyrites (Table 1), indicating a more extensive $\mathrm{U}(\mathrm{VI})$ reduction on Type II pyrites. Besides, the $\mathrm{U}(\mathrm{IV} / \mathrm{V}) / \mathrm{U}(\mathrm{VI})$ ratios decreased with increasing $\mathrm{pH}$ for each pyrite, resulting from a less surface adsorption 
(electrostatic repulsion) of cationic U(VI) species at lower $\mathrm{pH}$ (Figure S5) and/or the simultaneous occurrence of $\mathrm{U}(\mathrm{VI})$ precipitation at a relatively high $\mathrm{pH}$.

The $\mathrm{Fe}(2 p)$ spectra for U(VI)-reacted Type I pyrite can be fitted with three peaks located at $707.2 \pm 0.1,708.0 \pm 0.1$, and $709.7 \pm 0.2 \mathrm{eV}$, corresponding to $\mathrm{Fe}(\mathrm{II})-\mathrm{S}$ of pyrite, $\mathrm{Fe}(\mathrm{II})-\mathrm{O}$ of hydrated ferrous iron ${ }^{24}$ or $\mathrm{Fe}(\mathrm{III})-\mathrm{S}$ resulting from the breaking of $\mathrm{Fe}-\mathrm{S}$ bonds at the pyrite surface, ${ }^{44,52}$ and an $\mathrm{Fe}(\mathrm{II})$ satellite peak under acidic conditions or $\mathrm{Fe}(\mathrm{III})-\mathrm{O}$ probably coming from ferric oxyhydroxide under neutral to alkaline conditions, respectively. No obvious shape difference between Type I and Type II pristine pyrites was observed for both $\mathrm{Fe}(2 p)$ and $\mathrm{S}(2 p)$ spectra (Figure S6 and Table S6), as the depth probed by XPS $(\sim 5 \mathrm{~nm})$ is larger than the thickness of a surface layer (approximately one $\mathrm{Fe}(\mathrm{S})-\mathrm{S}$ bond length, i.e., a few angstroms). Compared with the pristine pyrite, the $\mathrm{Fe}(2 p)$ spectra of the U(VI)-reacted Type I pyrite are nearly identical (Figure S8). The $\mathrm{S}(2 p)$ spectra show the presence of oxidized sulfur (e.g., polysulfides or thiosulfate) and surface $S^{2-}$ at $164.0 \pm 0.6$ and $161.9 \pm 0.1 \mathrm{eV}$, respectively, together with the bulk $\mathrm{S}_{2}{ }^{2-}$ dimers located at $162.6 \pm 0.1 \mathrm{eV}$. These contributions are also observed for the pristine pyrites. In particular, no peak was observed above $166.4 \mathrm{eV}$ corresponding to the $\mathrm{BE}$ of $\mathrm{SO}_{3}{ }^{2-} / \mathrm{SO}_{4}{ }^{2-}$ for the pristine pyrites (Figure $\mathrm{S} 6$ ), suggesting that there was no surface oxidation during the anoxic grinding process. After reaction with U(VI), the characteristic band of $\mathrm{SO}_{3}{ }^{2-} / \mathrm{SO}_{4}{ }^{2-}$ located above $166.4 \mathrm{eV}$ is not observed for Type I pyrites. In contrast, for Type II pyrites of Pb-pII-pH6.5, Pb-pII-pH9.5, As-pII-pH6.5, and As-pIIpH9.5 (Figures S7 and S9), the characteristic peak of $\mathrm{SO}_{4}{ }^{2-}$ at $\sim 168.5 \mathrm{eV}$ appeared. Simultaneously, the $\mathrm{Fe}(2 p)$ spectra showed an apparent increase in the amplitude at $\sim 710.2 \mathrm{eV}$, indicating the occurrence of $\mathrm{Fe}(\mathrm{III})-\mathrm{O}$ compounds. The precipitation of $\mathrm{Fe}(\mathrm{III})$ oxyhydroxide might account for the $\mathrm{SO}_{4}{ }^{2-}$ detected at these $\mathrm{pH}$ conditions because of its good affinity to many anions, like $\mathrm{SO}_{4}{ }^{2-} \cdot{ }^{53}$ However, these products were not detected for Si-pyrite. The Fe(III)-oxyhydroxides product(s), together with the possible U(VI)-precipitate, might form 
passivation layers on pyrite surfaces and be another reason for the relatively slow reaction observed at $\mathrm{pH} \sim 9.5$.

In addition, a peak at $\sim 402 \mathrm{eV}$, which can be attributed to $\mathrm{NH}_{4}{ }^{+}(\mathrm{N} 1 \mathrm{~s}$ orbit), was observed on the reacted Type II $\mathrm{Pb}$ - and As-pyrites. As reported, both Fe(II) and S(-II) are able to reduce $\mathrm{NO}_{3}{ }^{-}$into $\mathrm{NH}_{4}{ }^{+}$, and the processes can be appreciably catalyzed by surface sites of Fe minerals. ${ }^{54,55}$ The occurrence of $\mathrm{NH}_{4}{ }^{+}$also verified the stronger reducing ability of Type II $\mathrm{Pb}$ - and As-pyrites compared with Type I pyrites. However, the signal of $\mathrm{NH}_{4}{ }^{+}$on reacted Type II Sipyrite was not enhanced obviously compared with Type I Si-pyrite (i.e., Si-pI-pH4.5), implying that the presence of Si impurity would not increase the reducing ability of pyrite.

\subsection{XANES characterization of uranium speciation}

The XANES spectra of U(VI)-reacted Type I and Type II Pb-pyrites and the reference XANES spectra for $\mathrm{UO}_{2}\left(\mathrm{NO}_{3}\right)_{2}, \mathrm{UO}_{3} \cdot 2 \mathrm{H}_{2} \mathrm{O}, \mathrm{U}_{3} \mathrm{O}_{8}, \mathrm{U}_{4} \mathrm{O}_{9}$, and $\mathrm{UO}_{2}$ are shown in Figure 3. A shift of the absorption edge toward lower energy from U(VI) standards to U(VI)-reacted pyrite samples can be observed, confirming the formation of reduced uranium on pyrite surfaces. The LCF analysis indicates that the combination of $\mathrm{UO}_{2}$ and $\mathrm{UO}_{3} \cdot 2 \mathrm{H}_{2} \mathrm{O}$ references gives the best fits to the experimental sample spectra (Table S7). Nevertheless, PHREEQC calculations using the NEA/OECD thermodynamic database ${ }^{56}$ suggested that the solubility of schoepite is higher than $0.1 \mathrm{mM}$ at $\mathrm{pH}<4.6$ (Figure $\mathrm{S} 10$ ). As the initial U(VI) loadings in the experiments were identical at $0.1 \mathrm{mM}$, a schoepite precipitate was therefore unlikely to form for the samples of $\mathrm{pH} \sim 3.0$ and $\sim 4.5$, which is also evidenced by the almost invariant $[\mathrm{U}(\mathrm{VI})]_{\mathrm{aq}}$ observed for Type I Pb- and As-pyrites at these two $\mathrm{pH}$ conditions (Figure 1). Additionally, it is worth noting that $\mathrm{UO}_{2}$ is strongly reactive toward $\mathrm{U}(\mathrm{VI})$ to form hyperstoichiometric $\mathrm{UO}_{2+\mathrm{x}}(\mathrm{s}),{ }^{57}$ although the reaction may be controlled by the relative amounts of these solids. Therefore, the formation of $\mathrm{UO}_{2}$ is unlikely in the presence of large unreduced U(VI) in this study. Regarding the $\mathrm{U} \mathrm{L}_{3}$-edge XANES spectroscopy analysis, its limited energy resolution and peak shape 
similarity of different references can allow us to draw only a general conclusion about the oxidation states of immobilized U, rather than the exact species. Nevertheless, the LCF analysis of the XANES data clearly demonstrated the occurrence of U(VI) reduction. As shown in Figure 3, all the powder sample spectra give a weak shoulder signal at $\sim 17180 \mathrm{eV}$, probably indicating the multiple scattering within the uranyl moiety ${ }^{58}$ and thus the possible presence of complexed uranyl structures on pyrite surfaces. However, adding $\mathrm{UO}_{2}\left(\mathrm{NO}_{3}\right)_{2}$ as the third standard in the LCF is not statistically significant enough from the F-test (Table S8). In future, more powerful techniques, e.g., $\mathrm{U} \mathrm{M}_{4}$-edge high-energy-resolution fluorescence detection (HERFD) XANES, ${ }^{33}$ will be considered to improve the identification of complex U species.

\subsection{Reactive surface sites detected by SEM-EDX}

Following the XPS and XANES analyses, SEM-EDX was used to image the surfaces of U(VI)-reacted pyrite and to determine the reactive sites where surface precipitates occur. Representative backscattered electron SEM images for Type II Pb-, As-, and Si-pyrite samples after reaction with $\mathrm{U}(\mathrm{VI})$ are shown in Figure 4 . The bright regions correspond to an enrichment of high $\mathrm{Z}$ number elements (i.e., heavy metals). In addition to the main elements of $\mathrm{Fe}$ and $\mathrm{S}$, the EDX spectra indicate the presence of $\mathrm{U}$ along with $\mathrm{Pb}$ for both $\mathrm{Pb}$-pyrite and $\mathrm{Si}$-pyrite and with As for As-pyrite (Table S9). Bright spots on pristine surfaces of the three Type II pyrites were also characterized by SEM-EDX analysis (Figure S11), suggesting an absence of U on the fresh surfaces. Spot explorations in dark areas show only the elements Fe and S (Spectra 2, 4, and 6 in Figure 4). These results indicate that U(VI) reduction preferentially occurred at $\mathrm{Pb}$ or As-impurity-rich spots on the pyrite surfaces, agreeing well with previous observations that freshly polished pyrite surfaces were efficient scavengers of aqueous U(VI) and that uranium distribution was heterogeneous on pyrite surfaces. ${ }^{26}$ The incorporation of $\mathrm{Pb}$ and As impurities into the pyrite structure can introduce additional defect states in the electronic structure of the stoichiometric crystal. The impurity defect states broaden to overlap the $\mathrm{FeS}_{2}$ conduction 
band, making the donated electrons delocalized. ${ }^{29}$ These delocalized electrons may lower the activation energy for the reaction, serving as reactive sites on the pyrite surface. It is likely that the grinding process could expose more impurity-rich sites that could also partially account for the observed U(VI) reduction. Nevertheless, these reactive impurity-rich sites could be removed by several cycles of acid wash, leaving a surface nearly inert toward aqueous U(VI). This situation was further confirmed by the SEM analysis prior to the experiments, as no (or fewer) heavy element regions were observed in the backscattered electron images for the acid-washed Type I As-pyrite (Figure S12).

\subsection{Possible reaction pathways}

Results of this work underline the importance of aqueous sulfide in U(VI) reduction. The surface $S^{2-}$ generated from anoxic grinding process would be partially consumed by the concurrent surface $\mathrm{Fe}^{3+}$ upon contact with water, and the rest would release into the solution and react with the subsequently added $U(V I)$. The occurrence of surface $S^{2-}$ species could partially account for the faster reaction kinetics observed for the Type II pyrites, in particular for the rapid $\mathrm{U}(\mathrm{VI})$ decrease in the first 24.5 hours (Figure 1).

Apart from the reaction involving surface $\mathrm{S}^{2-}$, the circular oxidation and reduction of $\mathrm{Fe}^{2+} / \mathrm{Fe}^{3+}$ species sorbed on pyrite surfaces, could be another important mechanism for U(VI) reduction. ${ }^{59}$ The occurrence of Fe(III)-O revealed by the XPS analysis for Type II pyrites of Pb-pII-pH6.5, Pb-pII-pH9.5, As-pII-pH6.5, and As-pII-pH9.5 also supports this mechanism, as intermediate $\mathrm{Fe}^{3+}$ is easy to precipitate by $\mathrm{OH}^{-}$at these $\mathrm{pH}$ conditions. The more facile pathway for $\mathrm{UO}_{2}{ }^{2+}$ reduction is to produce $\mathrm{UO}_{2}{ }^{+}$first, followed by the disproportionation of two intermediate $\mathrm{UO}_{2}{ }^{+}$ions. ${ }^{60}$ Ab initio electron transfer calculations reveal that the reduction of U(VI) to $\mathrm{U}(\mathrm{V})$ by $\mathrm{Fe}(\mathrm{II})_{\mathrm{aq}}$ (adsorbed on pyrite surface), considering an inner-sphere Fe-U complex electron transfer reaction, is both thermodynamically favored and kinetically rapid and is expected to occur in a heterogeneous system. ${ }^{61}$ The intermediate $\mathrm{UO}_{2}{ }^{+}$ions may be sta- 
bilized in the case of sorption onto mineral surfaces or be structurally incorporated into Fe (oxyhydr)oxide solid phase and formation of a uranate-type coordination environment, ${ }^{15,17,18}$ which might occur for the reactions at $\mathrm{pH} \sim 6.5$ and $\sim 9.5$ in this study. Previous study revealed that $\mathrm{U}_{4} \mathrm{O}_{9}$ and $\mathrm{U}_{3} \mathrm{O}_{8}$ are predominantly composed of $2 \mathrm{U}(\mathrm{IV})+2 \mathrm{U}(\mathrm{V})$ and $2 \mathrm{U}(\mathrm{V})+\mathrm{U}(\mathrm{VI})$, respectively. ${ }^{10}$ The incomplete reduction of U(VI) revealed by the XPS and XANES analyses supports the possible reaction pathways described by Eqs. (1) and/or (2), which are thermodynamically favorable as indicated by the negative $\Delta_{\mathrm{r}} \mathrm{G}^{0}$ values. ${ }^{56}$ Therefore, pyrite surfaces may serve as "incubators" for transforming the reduced $\mathrm{UO}_{2}{ }^{+}$ions into aliovalent oxides, such as $\mathrm{U}_{3} \mathrm{O}_{8}$ in combination with unreduced $\mathrm{U}(\mathrm{VI})$, or $\mathrm{U}_{4} \mathrm{O}_{9}$ in combination with $\mathrm{U}(\mathrm{IV})$ generated from the disproportionation of $\mathrm{UO}_{2}{ }^{+}$ions.

$$
\begin{aligned}
& 2 \mathrm{UO}_{2}{ }^{+}{ }_{(\mathrm{qq})}+\mathrm{UO}_{2}{ }^{2+}{ }_{(\mathrm{aq})}+2 \mathrm{H}_{2} \mathrm{O}_{(\mathrm{l})}=\mathrm{U}_{3} \mathrm{O}_{8(\mathrm{cr})}+4 \mathrm{H}^{+}{ }_{(\mathrm{aq})} \quad \Delta_{\mathrm{r}} \mathrm{G}^{0}=-20.598 \mathrm{~kJ} / \mathrm{mol} \\
& 2 \mathrm{UO}_{2}{ }^{+}{ }_{(\mathrm{aq})}+2 \mathrm{U}^{4+}{ }_{(\mathrm{aq})}+5 \mathrm{H}_{2} \mathrm{O}_{(\mathrm{l})}=\mathrm{U}_{4} \mathrm{O}_{9(\mathrm{cr})}+10 \mathrm{H}^{+}{ }_{(\mathrm{aq})} \quad \Delta_{\mathrm{r}} \mathrm{G}^{0}=-109.038 \mathrm{~kJ} / \mathrm{mol}
\end{aligned}
$$

Arsenic substitutions can result in a localized decrease of pyrite crystallinity, giving rise to a localized increase in the solubility and reactivity. ${ }^{62}$ Besides, the formation of AsS dianion groups is the most energetically favorable mechanism for arsenic incorporation into pyrite, leading to a local configuration that is very close to the one in arsenopyrite. ${ }^{43}$ The presence of AsS dianion groups can effectively trap electrons and accelerate the charge transfer between the liquid and pyrite surface, enhancing the oxidation rate of arsenic-containing pyrite. ${ }^{30}$ Preferential release of As impurities via arsenopyrite oxidation has previously been observed for As-rich pyrite oxidation by aqueous $\mathrm{Se}(\mathrm{IV}) .{ }^{4}$ Unlike As impurities, the pyrite lattice does not readily accommodate $\mathrm{Pb}$ at high concentrations, and the $\mathrm{Pb}$ content of pyrite was attributed to the presence of nano-scale inclusions of Pb-bearing minerals such as galena. ${ }^{28}$ Previous studies indicated that galena has priority over pyrite for U(VI) reduction, ${ }^{23,63}$ which further supports our study that the $\mathrm{Pb}$-rich area on the pyrite surface is the reactive site for U(VI) reduction. Given all the above information, arsenopyrite- and galena-like local configurations may 
be generated at As- and $\mathrm{Pb}$-rich spots, leading to the $\mathrm{U}(\mathrm{VI})$ reduction on the pyrite surfaces occurring prevalently via the reaction pathways of arsenopyrite and galena, respectively.

\subsection{Environmental implications}

Contamination caused by concentrated uranium may occur in many fields, e.g., the leaching and accumulation of uranium from a uranium mill tailing, ${ }^{64,65}$ or the failure of a nuclear waste canister in the future. The results of the present study are directly linked to the key geochemical processes that govern the mobility of toxic $\mathrm{U}$ in the environment. This study shows that surface $\mathrm{S}^{2-}$ and $\mathrm{Fe}^{3+}$ generated by breaking of $\mathrm{Fe}(\mathrm{S})-\mathrm{S}$ bonds during surface cleavage, as well as the minor $\mathrm{As}-\mathrm{Pb}$-impurity doping on pyrite surface, can largely accelerate the rate of aqueous U(VI) reduction by pyrite. These reactive surface species/sites can be removed by acid-washing, resulting in an inhibition of U(VI) reduction by pyrite, though thermodynamically favorable. In other words, the pyrite surface freshly polished or doped with trace element impurities is more efficient for U(VI) removal by reductive precipitation compared to the bulk phase or to the weathered/acid-washed surface.

Pyrite frequently found in igneous (e.g., granite), metamorphic and sedimentary (e.g., claystone) settings possesses different crystallinities. As illustrated in this study, the reactivity of well-crystalline pyrite is quite weak towards U(VI), leading to a poor effect on U(VI) immobilization in igneous host rocks (e.g., granite) of nuclear waste repositories where pyrite is present as an accessory mineral. Situations may differ for granite fractures, in which pyrite could also form under a low temperature groundwater environment and biogenic influence, and probably have various grain sizes, crystallinities, surface compositions, and thus different chemical reactivity towards $\mathrm{U}(\mathrm{VI}) .{ }^{66,67}$ In comparison, the pyrite precipitating at ambient temperature in flooded soils and sediments, and at former mining and processing sites is usually characterized by poorer crystallinity, smaller size, more lattice defects, more impurity doping, and higher solubility, and thus is expected to be more reactive towards $\mathrm{U}(\mathrm{VI}) .^{13}$ This kind of 
pyrite is able to reduce $\mathrm{U}(\mathrm{VI})$ and accumulate $\mathrm{U}$ effectively in the surroundings if the soil/sediment can stay reducing (i.e. depending on the persistence of redox oscillations ${ }^{68}$ ), which is evidenced by the widespread co-existence of pyrites and $U$ precipitates in sediments. ${ }^{20}$ Therefore, the mobility of uranium is presumed to be largely attenuated by the pyrite present in sedimentary materials, e.g., claystone that is also widely considered for a bedrock barrier in nuclear waste disposal. The findings in this study could improve our understanding of the geochemical behavior of $U$ in the presence of pyrite in the relevant environments.

\section{ASSOCIATED CONTENT}

Supporting Information Available. Additional materials referenced in the text are available free of charge.

XRD patterns of synthesized schoepite and natural pyrites. PDFs, S K-edge XAFS spectra, XPS spectra, BSE images, and EDX spectra of pristine pyrites. XPS spectra of U(VI)-reacted pyrites. Aqueous U(VI) speciation and schoepite dissolution with $\mathrm{pH}$ values. Aqueous results of reactors with Type I and Type II pyrites. Aqueous results for verifying S(-II) and S(0) species. Fitting results of XPS, S K-edge EXAFS, and U L -edge XANES. F-tests for LCF of U $\mathrm{L}_{3}$-edge XANES. Elemental contents determined by EDX spectroscopy.

\section{AUTHOR INFORMATION}

\section{Corresponding Author}

*Phone: +86(0) 756 3668392. E-mail: kangml3@mail.sysu.edu.cn (M. KANG).

\section{Notes}

The authors declare no competing financial interest.

\section{ACKNOWLEDGMENTS}


The authors are grateful to Eugene S. Ilton (PNNL, USA) for the XPS data interpretation and Robin Pauer (Empa, Switzerland) for the EDX spectrum treatment. This work was financially supported by the National Natural Science Foundation of China (NSFC, Nos. 41773095 and 41403075), the Fundamental Research Funds for the Central Universities of Sun Yat-sen University (No. 201545000-31610011), ANDRA, and Labex OSUG@2020 (Investissements d'avenir - ANR10 LABX56). Bin Ma also appreciates the financial support from the China Scholarship Council (CSC) and European Union's Horizon 2020 research and innovation programme under the Marie Skłodowska-Curie grant agreement number 754364. The synchrotron facilities ESRF (BM25A-25-01-976) are acknowledged for the allocation of beam time.

\section{REFERENCES}

(1) Gaucher, É. C.; Blanc, P.; Bardot, F.; Braibant, G.; Buschaert, S.; Crouzet, C.; Gautier, A.; Girard, J.-P.; Jacquot, E.; Lassin, A. Modelling the porewater chemistry of the CallovianOxfordian formation at a regional scale. C.R. Geosci. 2006, 338 (12-13), 917-930.

(2) Ma, B.; Fernandez-Martinez, A.; Wang, K.; Madé, B.; Henocq, P.; Tisserand, D.; Bureau, S.; Charlet, L. Selenite Sorption on Hydrated CEM-V/A Cement in the Presence of Steel Corrosion Products: Redox vs. Nonredox Sorption. Environ. Sci. Technol. 2020, 54 (4), 23442352 .

(3) Badaut, V.; Schlegel, M. L.; Descostes, M.; Moutiers, G. In situ time-resolved X-ray nearedge absorption spectroscopy of selenite reduction by siderite. Environ. Sci. Technol. 2012, 46 (19), 10820-10826.

(4) Kang, M.; Bardelli, F.; Charlet, L.; Géhin, A.; Shchukarev, A.; Chen, F.; Morel, M.-C.; Ma, B.; Liu, C. Redox reaction of aqueous selenite with As-rich pyrite from Jiguanshan ore mine (China): Reaction products and pathway. Appl. Geochem. 2014, 47, 130-140. 
(5) Huo, L.; Xie, W.; Qian, T.; Guan, X.; Zhao, D. Reductive immobilization of pertechnetate in soil and groundwater using synthetic pyrite nanoparticles. Chemosphere 2017, 174, 456465.

(6) Townsend, L. T.; Shaw, S.; Ofili, N. E. R.; Kaltsoyannis, N.; Walton, A. S.; Mosselmans, J. F. W.; Neill, T. S.; Lloyd, J. R.; Heath, S.; Hibberd, R.; Morris, K. Formation of a U(VI)persulfide complex during environmentally relevant sulfidation of iron (oxyhydr)oxides. Environ. Sci. Technol. 2020, 54 (1), 129-136.

(7) Ma, B.; Charlet, L.; Fernandez-Martinez, A.; Kang, M.; Madé, B. A review of the retention mechanisms of redox-sensitive radionuclides in multi-barrier systems. Appl. Geochem. 2019, 100, 414-431.

(8) Faybishenko, B.; Birkholzer, J.; Sassani, D.; Swift, P., Eds. International Approaches for Deep Geological Disposal of Nuclear Waste: Geological Challenges in Radioactive Waste Isolation: Fifth Worlwide Review; Lawrence Berkeley National Laboratory, Sandia National Laboratories, 2016.

(9) Chen, P.; Ma, Y.; Kang, M.; Shang, C.; Song, Y.; Xu, F.; Wang, J.; Song, G.; Yang, Y. The redox behavior of uranium on Beishan granite: Effect of $\mathrm{Fe}^{2+}$ and $\mathrm{Fe}^{3+}$ content. J. Environ. Radioact. 2020, 217, https://doi.org/10.1016/j.jenvrad.2020.106208.

(10) Kvashnina, K.; Butorin, S. M.; Martin, P.; Glatzel, P. Chemical state of complex uranium oxides. Phys. Rev. Lett. 2013, 111 (25), 253002.

(11) Dong, W.; Brooks, S. C. Determination of the formation constants of ternary complexes of uranyl and carbonate with alkaline earth metals $\left(\mathrm{Mg}^{2+}, \mathrm{Ca}^{2+}, \mathrm{Sr}^{2+}\right.$, and $\left.\mathrm{Ba}^{2+}\right)$ using anion exchange method. Environ. Sci. Technol. 2006, 40 (15), 4689-4695.

(12) Guo, X.; Szenknect, S.; Mesbah, A.; Clavier, N.; Poinssot, C.; Ushakov, S. V.; Curtius, H.; Bosbach, D.; Ewing, R. C.; Burns, P. C. Thermodynamics of formation of coffinite, $\mathrm{USiO}_{4}$. Proc. Natl. Acad. Sci. U.S.A. 2015, 112 (21), 6551-6555. 
(13) Wang, Y.; Bagnoud, A.; Suvorova, E.; McGivney, E.; Chesaux, L.; Phrommavanh, V.; Descostes, M.; Bernier-Latmani, R. Geochemical control on uranium(IV) mobility in a mining-impacted wetland. Environ. Sci. Technol. 2014, 48 (17), 10062-10070.

(14) Chakraborty, S.; Favre, F.; Banerjee, D.; Scheinost, A. C.; Mullet, M.; Ehrhardt, J.-J.; Brendle, J.; Vidal, L.; Charlet, L. U(VI) sorption and reduction by Fe(II) sorbed on montmorillonite. Environ. Sci. Technol. 2010, 44 (10), 3779-3785.

(15) Ilton, E. S.; Boily, J.-F.; Buck, E. C.; Skomurski, F. N.; Rosso, K. M.; Cahill, C. L.; Bargar, J. R.; Felmy, A. R. Influence of dynamical conditions on the reduction of $\mathrm{U}^{\mathrm{VI}}$ at the magnetite-solution interface. Environ. Sci. Technol. 2010, 44 (1), 170-176.

(16) Veeramani, H.; Scheinost, A. C.; Monsegue, N.; Qafoku, N. P.; Kukkadapu, R.; Newville, M.; Lanzirotti, A.; Pruden, A.; Murayama, M.; Hochella Jr, M. F. Abiotic reductive immobilization of U(VI) by biogenic mackinawite. Environ. Sci. Technol. 2013, 47 (5), 23612369.

(17) Ilton, E. S.; Pacheco, J. S. L.; Bargar, J. R.; Shi, Z.; Liu, J.; Kovarik, L.; Engelhard, M. H.; Felmy, A. R. Reduction of U(VI) incorporated in the structure of hematite. Environ. Sci. Technol. 2012, 46 (17), 9428-9436.

(18) Roberts, H. E.; Morris, K.; Law, G. T.; Mosselmans, J. F. W.; Bots, P.; Kvashnina, K.; Shaw, S. Uranium (V) incorporation mechanisms and stability in $\mathrm{Fe}(\mathrm{II}) / \mathrm{Fe}(\mathrm{III})$ (oxyhydr) oxides. Environ. Sci. Technol. Lett. 2017, 4 (10), 421-426.

(19) England, G. L.; Rasmussen, B.; Krapež, B.; Groves, D. I. The origin of uraninite, bitumen nodules, and carbon seams in Witwatersrand gold-uranium-pyrite ore deposits, based on a Permo-Triassic analogue. Econ. Geol. 2001, 96 (8), 1907-1920.

(20) Cumberland, S. A.; Douglas, G.; Grice, K.; Moreau, J. W. Uranium mobility in organic matter-rich sediments: A review of geological and geochemical processes. Earth Sci. Rev. 2016, 159, 160-185. 
(21) Yang, Z.; Kang, M.; Ma, B.; Xie, J.; Chen, F.; Charlet, L.; Liu, C. Inhibition of U(VI) reduction by synthetic and natural pyrite. Environ. Sci. Technol. 2014, 48 (18), 10716-10724. (22) Bone, S. E.; Dynes, J. J.; Cliff, J.; Bargar, J. R. Uranium (IV) adsorption by natural organic matter in anoxic sediments. Proc. Natl. Acad. Sci. U.S.A. 2017, 114 (4), 711-716.

(23) Wersin, P.; Hochella Jr, M. F.; Persson, P.; Redden, G.; Leckie, J. O.; Harris, D. W. Interaction between aqueous uranium (VI) and sulfide minerals: Spectroscopic evidence for sorption and reduction. Geochim. Cosmochim. Acta 1994, 58 (13), 2829-2843.

(24) Descostes, M.; Schlegel, M.; Eglizaud, N.; Descamps, F.; Miserque, F.; Simoni, E. Uptake of uranium and trace elements in pyrite $\left(\mathrm{FeS}_{2}\right)$ suspensions. Geochim. Cosmochim. Acta 2010, 74 (5), 1551-1562.

(25) Eglizaud, N.; Miserque, F.; Simoni, E.; Schlegel, M.; Descostes, M. Uranium (VI) interaction with pyrite $\left(\mathrm{FeS}_{2}\right)$ : Chemical and spectroscopic studies. Radiochim. Acta 2006, 94 (9-11), 651-656.

(26) Scott, T.; Tort, O. R.; Allen, G. Aqueous uptake of uranium onto pyrite surfaces; reactivity of fresh versus weathered material. Geochim. Cosmochim. Acta 2007, 71 (21), 5044-5053.

(27) Bruggeman, C.; Maes, N. Uptake of uranium(VI) by pyrite under Boom Clay conditions: Influence of dissolved organic carbon. Environ. Sci. Technol. 2010, 44 (11), 4210-4216.

(28) Abraitis, P.; Pattrick, R.; Vaughan, D. Variations in the compositional, textural and electrical properties of natural pyrite: A review. Int. J. Miner. Process. 2004, 74 (1-4), 41-59. (29) Lehner, S.; Savage, K. The effect of As, Co, and Ni impurities on pyrite oxidation kinetics: Batch and flow-through reactor experiments with synthetic pyrite. Geochim. Cosmochim. Acta 2008, 72 (7), 1788-1800. 
(30) Lehner, S.; Savage, K.; Ciobanu, M.; Cliffel, D. E. The effect of As, Co, and Ni impurities on pyrite oxidation kinetics: An electrochemical study of synthetic pyrite. Geochim. Cosmochim. Acta 2007, 71 (10), 2491-2509.

(31) Wan, M.; Shchukarev, A.; Lohmayer, R.; Planer-Friedrich, B.; Peiffer, S. Occurrence of surface polysulfides during the interaction between ferric (hydr)oxides and aqueous sulfide. Environ. Sci. Technol. 2014, 48 (9), 5076-5084.

(32) McGuire, M. M.; Hamers, R. J. Extraction and quantitative analysis of elemental sulfur from sulfide mineral surfaces by high-performance liquid chromatography. Environ. Sci. Technol. 2000, 34 (21), 4651-4655.

(33) Bès, R.; Rivenet, M.; Solari, P.-L.; Kvashnina, K. O.; Scheinost, A. C.; Martin, P. M. Use of HERFD-XANES at the $\mathrm{U} \mathrm{L}_{3}$-and $\mathrm{M}_{4}$-edges to determine the uranium valence state on $\left[\mathrm{Ni}\left(\mathrm{H}_{2} \mathrm{O}\right)_{4}\right]_{3}\left[\mathrm{U}\left(\mathrm{OH}, \mathrm{H}_{2} \mathrm{O}\right)\left(\mathrm{UO}_{2}\right)_{8} \mathrm{O}_{12}(\mathrm{OH})_{3}\right]$. Inorg. Chem. 2016, 55 (9), 4260-4270.

(34) Opel, K.; Weiss, S.; Hübener, S.; Zänker, H.; Bernhard, G. Study of the solubility of amorphous and crystalline uranium dioxide by combined spectroscopic methods. Radiochim. Acta 2007, 95 (3), 143-149.

(35) Ravel, B.; Newville, M., ATHENA, ARTEMIS, HEPHAESTUS: data analysis for X-ray absorption spectroscopy using IFEFFIT. J. Synchrotron Radiat. 2005, 12 (4), 537-541.

(36) Rimondi, V.; Bardelli, F.; Benvenuti, M.; Costagliola, P.; Gray, J. E.; Lattanzi, P. Mercury speciation in the Mt. Amiata mining district (Italy): Interplay between urban activities and mercury contamination. Chem. Geol. 2014, 380, 110-118.

(37) Downward, L.; Booth, C.; Lukens, W.; Bridges, F. In A Variation of the F-Test for Determining Statistical Relevance of Particular Parameters in EXAFS Fits, $13^{\text {th }}$ International Conference on X-ray Absorption Fine Structure, Stanford, CA, USA, July 9-14, 2006; AIP Conf. Proc.; American Institute of Physics (AIP): Melville, NY, 2007; pp 129-131. 
(38) Ma, B.; Fernandez-Martinez, A.; Grangeon, S.; Tournassat, C.; Findling, N.; Carrero, S.; Tisserand, D.; Bureau, S.; Elkaïm, E.; Marini, C.; Aquilanti, G.; Koishi, A.; Marty, N. C. M.; Charlet, L. Selenite uptake by Ca-Al LDH: A description of intercalated anion coordination geometries. Environ. Sci. Technol. 2018, 52 (3), 1624-1632.

(39) Fujii, T.; Yoshida, A.; Tanaka, K.; Marumo, F.; Noda, Y. High pressure compressibilities of pyrite and cattierite. Mineral. J. 1986, 13 (4), 202-211.

(40) Vjunov, A.; Fulton, J. L.; Huthwelker, T.; Pin, S.; Mei, D.; Schenter, G. K.; Govind, N.; Camaioni, D. M.; Hu, J. Z.; Lercher, J. A. Quantitatively probing the Al distribution in zeolites. J. Am. Chem. Soc. 2014, 136 (23), 8296-8306.

(41) Kosmulski, M. pH-dependent surface charging and points of zero charge. IV. Update and new approach. J. Colloid Interface Sci. 2009, 337 (2), 439-448.

(42) Le Pape, P.; Blanchard, M.; Brest, J.; Boulliard, J.-C.; Ikogou, M.; Stetten, L.; Wang, S.; Landrot, G.; Morin, G. Arsenic incorporation in pyrite at ambient temperature at both tetrahedral $\mathrm{S}^{-\mathrm{I}}$ and octahedral $\mathrm{Fe}^{\mathrm{II}}$ sites: Evidence from EXAFS-DFT analysis. Environ. Sci. Technol. 2017, 51 (1), 150-158.

(43) Blanchard, M.; Alfredsson, M.; Brodholt, J.; Wright, K.; Catlow, C. R. A. Arsenic incorporation into $\mathrm{FeS}_{2}$ pyrite and its influence on dissolution: A DFT study. Geochim. Cosmochim. Acta 2007, 71 (3), 624-630.

(44) Nesbitt, H.; Bancroft, G.; Pratt, A.; Scaini, M. Sulfur and iron surface states on fractured pyrite surfaces. Am. Mineral. 1998, 83 (9-10), 1067-1076.

(45) Hua, B.; Xu, H. F.; Terry, J., Deng, B. L. Kinetics of uranium(VI) reduction by hydrogen sulfide in anoxic aqueous systems. Environ. Sci. Technol. 2006, 40, 4666-4671.

(46) Hyun, S. P.; Davis, J. A.; Hayes, K. F. Abiotic U(VI) reduction by aqueous sulfide. Appl. Geochem. 2014, 50, 7-15. 
(47) Luo, M.; Liu, S.; Li, J.; Luo, F.; Lin, H.; Yao, P. Uranium sorption characteristics onto synthesized pyrite. J. Radioanal. Nucl. Chem. 2016, 307 (1), 305-312.

(48) Renock, D.; Mueller, M.; Yuan, K.; Ewing, R. C.; Becker, U. The energetics and kinetics of uranyl reduction on pyrite, hematite, and magnetite surfaces: A powder microelectrode study. Geochim. Cosmochim. Acta 2013, 118, 56-71.

(49) Ilton, E. S.; Bagus, P. S. XPS determination of uranium oxidation states. Surf. Interface Anal. 2011, 43 (13), 1549-1560.

(50) Massey, M. S.; Lezama-Pacheco, J. S.; Jones, M. E.; Ilton, E. S.; Cerrato, J. M.; Bargar, J. R.; Fendorf, S. Competing retention pathways of uranium upon reaction with Fe(II). Geochim. Cosmochim. Acta 2014, 142, 166-185.

(51) Ilton, E. S.; Du, Y.; Stubbs, J. E.; Eng, P. J.; Chaka, A. M.; Bargar, J. R.; Nelin, C. J.; Bagus, P. S. Quantifying small changes in uranium oxidation states using XPS of a shallow core level. Phys. Chem. Chem. Phys. 2017, 19 (45), 30473-30480.

(52) Elsetinow, A. R.; Guevremont, J. M.; Strongin, D. R.; Schoonen, M. A.; Strongin, M. Oxidation of $\{100\}$ and $\{111\}$ surfaces of pyrite: Effects of preparation method. Am. Mineral. 2000, 85 (3-4), 623-626.

(53) Rietra, R. P.; Hiemstra, T.; van Riemsdijk, W. H. Sulfate adsorption on goethite. J. Colloid Interface Sci. 1999, 218 (2), 511-521.

(54) Ottley, C. J.; Davison, W.; Edmunds, W. M. Chemical catalysis of nitrate reduction by iron (II). Geochim. Cosmochim. Acta 1997, 61 (9), 1819-1828.

(55) Brunet, R. C.; Garcia-Gil, L. J. Sulfide-induced dissimilatory nitrate reduction to ammonia in anaerobic freshwater sediments. FEMS Microbiol. Ecol. 1996, 21 (2), 131-138.

(56) Hummel, W.; Mompean, F. J.; Illemassène, M.; Perrone, J. Chemical thermodynamics of compounds and complexes of $U, N p, P u, A m, T c, S e, N i$ and $\mathrm{Zr}$ with selected organic ligands; Elsevier Science, 2005; Vol. 9. 
(57) Cui, D.; Spahiu, K. On the interaction between uranyl carbonate and $\mathrm{UO}_{2}(\mathrm{~s})$ in anaerobic solution. J. Nucl. Sci. Technol. 2002, 39 (sup3), 500-503.

(58) Hudson, E.; Allen, P.; Terminello, L.; Denecke, M.; Reich, T. Polarized X-rayabsorption spectroscopy of the uranyl ion: Comparison of experiment and theory. Phys. Rev. B: Condens. Matter 1996, 54 (1), 156.

(59) Moses, C. O.; Herman, J. S. Pyrite oxidation at circumneutral pH. Geochim. Cosmochim. Acta 1991, 55 (2), 471-482.

(60) Yuan, K.; Renock, D.; Ewing, R. C.; Becker, U. Uranium reduction on magnetite: Probing for pentavalent uranium using electrochemical methods. Geochim. Cosmochim. Acta 2015, 156, 194-206.

(61) Taylor, S.; Marcano, M.; Rosso, K. M.; Becker, U. An experimental and ab initio study on the abiotic reduction of uranyl by ferrous iron. Geochim. Cosmochim. Acta 2015, 156, 154172.

(62) Qiu, G.; Gao, T.; Hong, J.; Tan, W.; Liu, F.; Zheng, L. Mechanisms of arsenic-containing pyrite oxidation by aqueous arsenate under anoxic conditions. Geochim. Cosmochim. Acta 2017, 217, 306-319.

(63) Aubriet, H.; Humbert, B.; Perdicakis, M. Interaction of U(VI) with pyrite, galena and their mixtures: A theoretical and multitechnique approach. Radiochim. Acta 2006, 94 (9-11), 657-663.

(64) Abdelouas, A. Uranium mill tailings: geochemistry, mineralogy, and environmental impact. Elements 2006, 2 (6), 335-341.

(65) Yin, M.; Tsang, D. C. W.; Sun, J.; Wang, J.; Shang, J.; Fang, F.; Wu, Y.; Liu, J.; Song, G.; Xiao, T.; Chen, D. Critical insight and indication on particle size effects towards uranium release from uranium mill tailings: Geochemical and mineralogical aspects. Chemosphere 2020, 250, 126315. 
(66) Nishimoto, S.; Yoshida, H. Hydrothermal alteration of deep fractured granite: Effects of dissolution and precipitation. Lithos 2010, 115 (1), 153-162.

(67) Sahlstedt, E.; Karhu, J. A.; Pitkänen, P.; Whitehouse, M. Implications of sulfur isotope fractionation in fracture-filling sulfides in crystalline bedrock, Olkiluoto, Finland. Appl. Geochem. 2013, 32, 52-69.

(68) Couture, R.-M.; Charlet, L.; Markelova, E.; Madé, B. t.; Parsons, C. T. On-off mobilization of contaminants in soils during redox oscillations. Environ. Sci. Technol. 2015, 49 (5), 3015-3023. 
Table 1. Summary of the fitted XPS data for U(VI)-reacted pyrite. ${ }^{\text {a }}$ The analytical BE uncertainty of the $\mathrm{U}\left(4 f_{7 / 2}\right)$ spin-orbit peak is $\pm 0.2 \mathrm{eV}$. Uncertainties of area ratios of $\mathrm{U}(\mathrm{IV} / \mathrm{V}) / \mathrm{U}(\mathrm{VI})$ are given by the numbers in brackets on the last digit, i.e., $0.23(6)$ represents $0.23 \pm 0.06$, $1.19(15)$ represents $1.19 \pm 0.15$.

\begin{tabular}{cccccc}
\hline Samples & Fe(III)-O & $\mathrm{SO}_{4}{ }^{2-}$ & $\begin{array}{c}\mathrm{BE}-\mathrm{U}(\mathrm{VI}) \\
(\mathrm{eV})\end{array}$ & $\begin{array}{c}\mathrm{BE}-\mathrm{U}(\mathrm{IV} / \mathrm{V}) \\
(\mathrm{eV})\end{array}$ & Area ratio of U(IV/V)/U(VI) \\
\hline Pb-pI-pH6.5 & $\mathrm{Y}$ & $\mathrm{N}$ & 381.9 & 380.6 & $0.23(6)$ \\
As-pI-pH6.5 & $\mathrm{Y}$ & $\mathrm{N}$ & 381.8 & 380.5 & $0.21(2)$ \\
Si-pI-pH4.5 & $\mathrm{P}$ & $\mathrm{N}$ & 382.0 & 380.6 & $0.34(8)$ \\
Pb-pII-pH3.0 & $\mathrm{P}$ & $\mathrm{N}$ & 381.8 & 380.4 & $1.19(15)$ \\
Pb-pII-pH4.5 & $\mathrm{P}$ & $\mathrm{N}$ & 381.9 & 380.4 & $0.60(14)$ \\
Pb-pII-pH6.5 & $\mathrm{Y}$ & $\mathrm{Y}$ & 381.8 & 380.4 & $0.50(22)$ \\
Pb-pII-pH9.5 & $\mathrm{Y}$ & $\mathrm{Y}$ & 382.0 & 380.4 & $0.25(7)$ \\
As-pII-pH3.0 & $\mathrm{P}$ & $\mathrm{N}$ & 382.0 & 380.4 & $1.99(52)$ \\
As-pII-pH4.5 & $\mathrm{P}$ & $\mathrm{N}$ & 381.7 & 380.5 & $0.85(70)$ \\
As-pII-pH6.5 & $\mathrm{Y}$ & $\mathrm{Y}$ & 382.2 & 380.5 & $0.183(26)$ \\
As-pII-pH9.5 & $\mathrm{Y}$ & $\mathrm{Y}$ & 382.1 & 380.4 & $0.19(8)$ \\
Si-pII-pH4.5 & $\mathrm{P}$ & $\mathrm{N}$ & 382.3 & 380.5 & $385(85)$ \\
Si-pII-pH6.5 & $\mathrm{Y}$ & $\mathrm{N}$ & 381.7 & 380.4 & 380.5 \\
Si-pII-pH9.5 & $\mathrm{Y}$ & $\mathrm{N}$ & 381.8 & & $0.29(5)$ \\
\hline
\end{tabular}

${ }^{\text {a }} \mathrm{Y}$ indicates an observed signal; $\mathrm{P}$ represents a possible signal; $\mathrm{N}$ suggests no visible signal. 


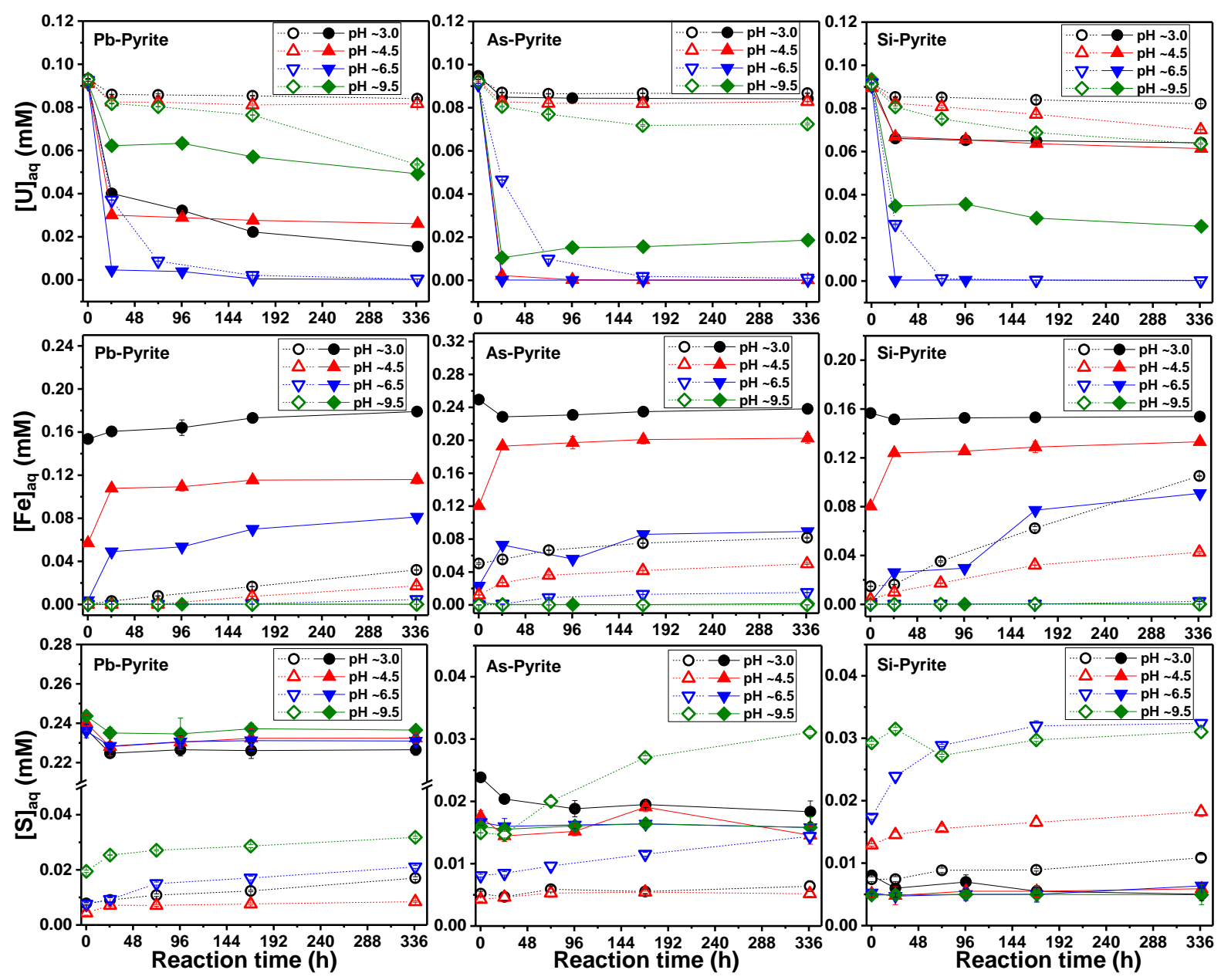

Figure 1. Concentration evolutions of aqueous $\mathrm{U}, \mathrm{Fe}$ and $\mathrm{S}$ under various $\mathrm{pH}$ conditions as functions of time. The hollow symbols linked with short dash lines represents the results for Type I pyrite, while the solid symbols linked with solid lines for Type II pyrite. 

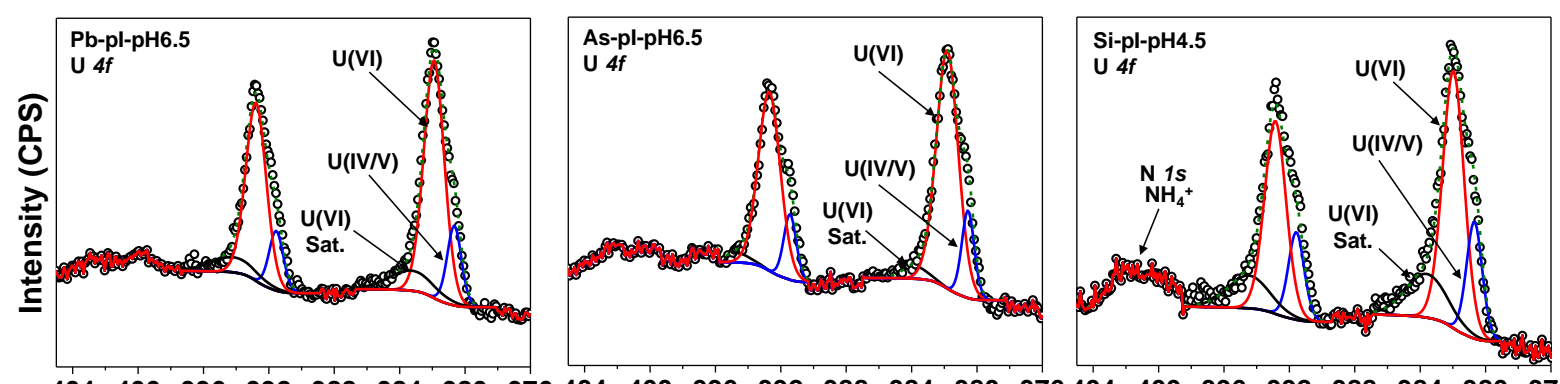

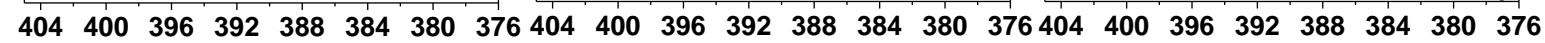
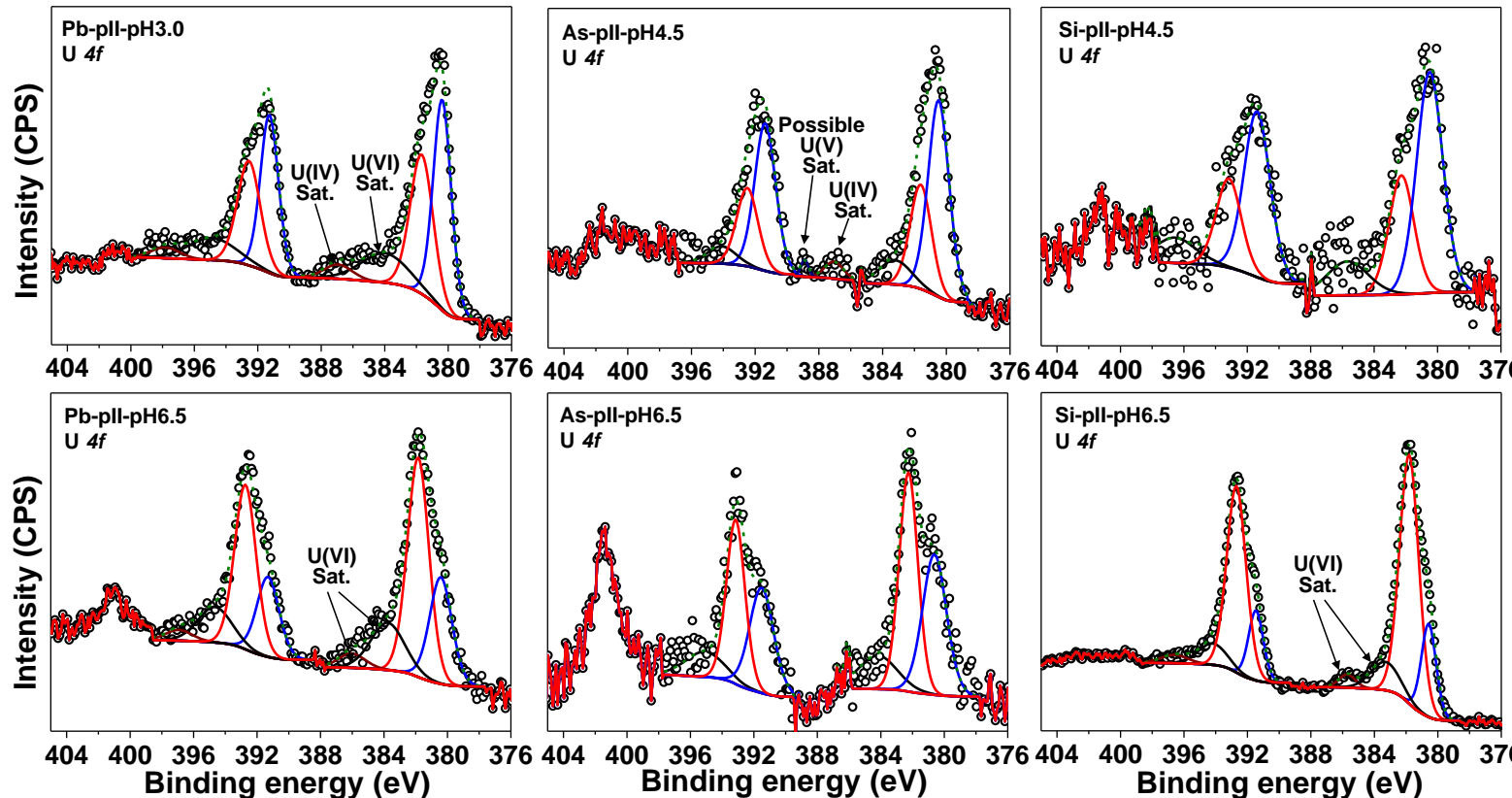

Binding energy $(\mathrm{eV})$ Binding energy $(\mathrm{eV})$

Binding energy $(\mathrm{eV})$

Figure 2. Fitted U( $4 f)$ XPS spectra for U(VI)-reacted pyrite. Sat. represents the satellite peak. 


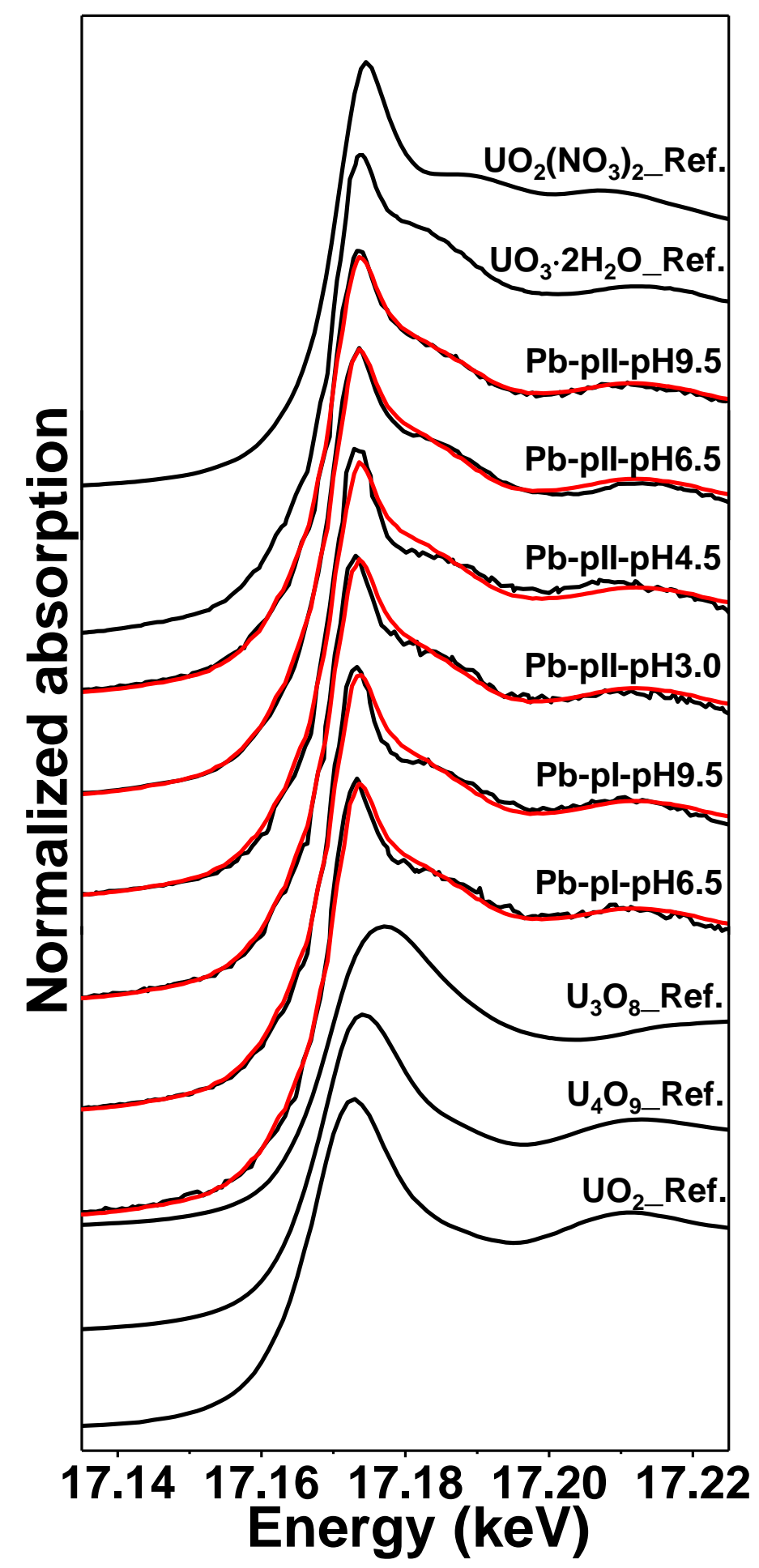

Figure 3. Normalized $\mathrm{U} \mathrm{L}_{3}$-edge XANES spectra and the LCF results of U(VI)-reacted $\mathrm{Pb}$ pyrite samples. Red lines are the fits of the experimental spectra. 


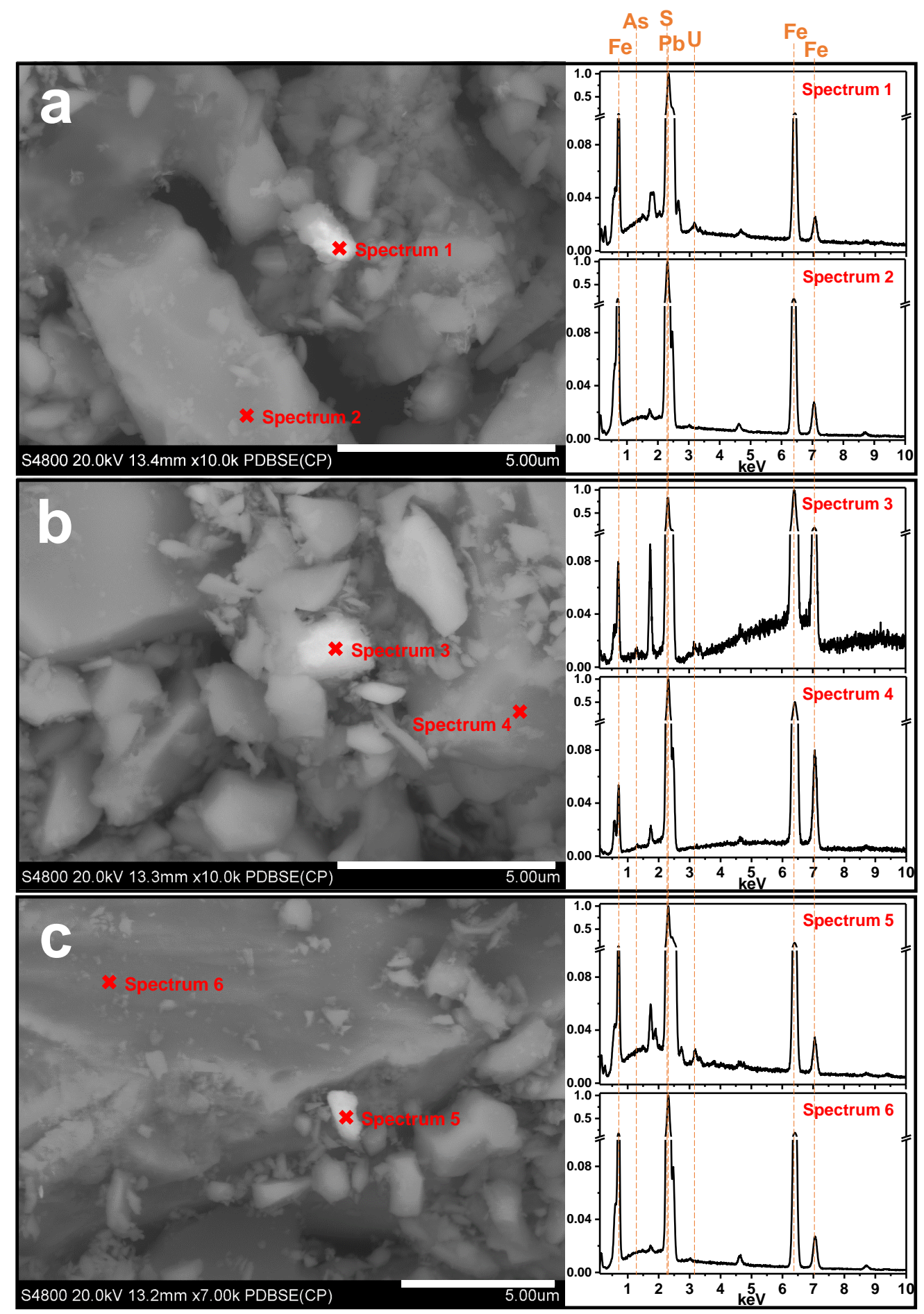

Figure 4. Backscattered electron (BSE) images of (a) Pb-pII-pH6.5, (b) As-pII-pH3.0, and (c) Si-pII-pH6.5. The corresponding normalized EDX spectra of selected spots are shown to the right of each SEM image. Elemental contents of the selected spots are shown in Table S9. 
Table of Contents (TOC)

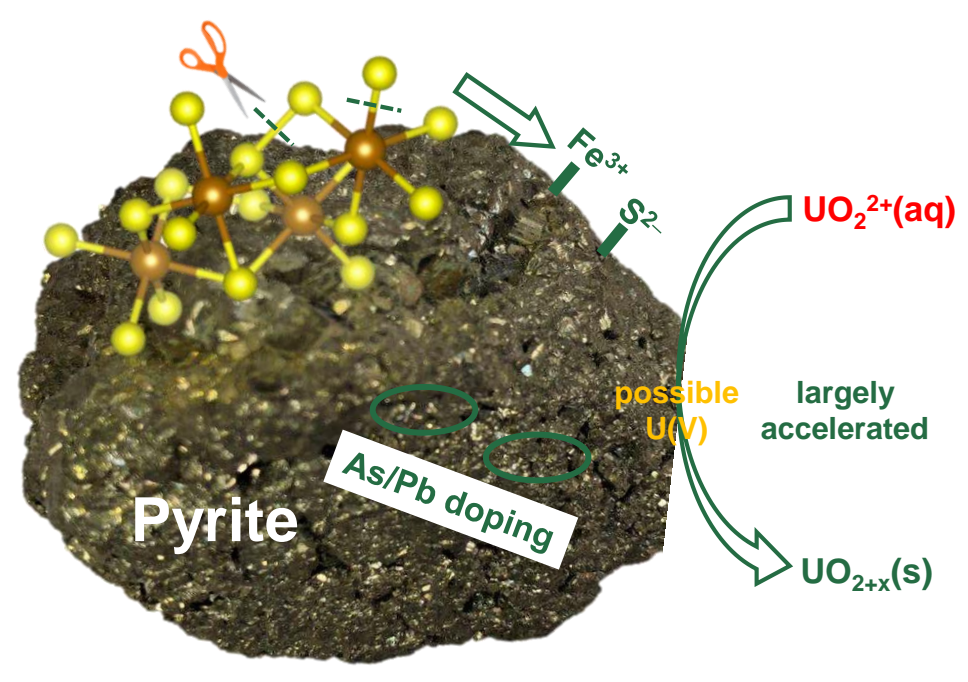

